\title{
The Phenomenon of Visuality in the Context of Musical Pieces by Siberian Composers
}

\author{
Irina Belonosova \\ Krasnoyarsk State Institute of Arts \\ Krasnoyarsk, Russia \\ E-mail: irinabelay@bk.ru
}

\begin{abstract}
The article considers peculiarities of musical pieces of various genres by Siberian composers, the visual imagery in which functions on equal terms along with the musical expressive means. The audio component combined with the visual one results in the formation of an audiovisual text beyond the cinematographic art. Musical pieces of this type have specific features of synthetic genres. Despite the unquestionable originality of the whole, the analyzed pieces demonstrate a connection with the program music. In audiovisual compositions, the verbally expressed literary program is replaced by the visualized program embodied in the visual component.
\end{abstract}

Keywords-music; art; audiovisual text; synthetic genre; composers of Siberia

\section{INTRODUCTION}

At the turn of the 20th-21st centuries the musical trends, connected with the introduction of the scientific and technological progress achievements in the arsenal of expressive music means, continue to develop in musical culture. Appearance of the newest information transfer technology in the 20th century based on two perception channels - verbal (audio) and visual - could not but lead to their synthesis.

\section{THE OBJECTIVE OF THE RESEARCH}

The objective of the research is to consider the functions of music in synthetic compositions of Siberian composers, which are not connected with cinematographic art but use the visual imagery: I. Fleisher The Morning of Streltsy Execution (based on the painting by V.I. Surikov). Music for oboe, percussion instruments, and string orchestra (2003), Yu. Ashchepkov Heavenly Russia. Electronic composition to the video catalog by L.Klyuchnikova (2009), Yu. Yukechev's photo novel The Holocaust (2015).

\section{A. Research Methods}

The material for this article included the videotapes of the above compositions and the information on some of them in various mass media and the Internet. The novelty of the studied musical pieces required to use the approaches to the analysis of media music offered by T. Shak along with the common methods of theoretical musicology [1].

\section{OVERVIEW OF LITERATURE IN CONNECTION WITH THE RESEARCH TOPIC}

Appearance of audiovisual compositions is inseparable from media genres, namely cinematic music. Media text, media genre, media education - these are just some of the new terms and notions, which are being actively used in the analysis of the new branch of the modern culture namely defined as media culture [2]. The musical component of media texts varies up to complete absence of music, for example, in journalistic texts. In terms of music synthesized compositions when music is combined with media means of information transfer refer to supplementary genres. Peculiarities of music functioning in cinema art are studied in more detail by T. Shak [3].

The informative saturation and vitality of synthetic genres, in which music is present, is confirmed by the course of the whole history of musical culture. The connection of music and word is especially outlined in the program instrumental music (programmusik in German, musique a programme in French, musica a programma in Italian, English programme music in English). In such works, the content is specified either in the title or in a specially prescribed program that can be embodied in verse or prose texts. For example, all pieces of the piano cycle The Seasons by Pyotr Ilyich Tchaikovsky have names and poetic epigraphs.

The visual impressions that influenced the composer, which had become impulses to the creation of musical pieces, demonstrate the interconnection of music and painting, sounds and colors. The possibilities of interconnection of these two types of world perception - audio and visual - have been known since Aristotle [4]. There are many interesting and fundamental works devoted to the appearance of the so called "color hearing" among the composers, the influence of the art component on the music of N. A. Rimsky-Korsakov, K. Debussia, M. Čiurlionis and others [5].

The novelty of this article is due to consideration of peculiarities of musical pieces, which can be both referred to program and media compositions. 


\section{RESEARCH RESULTS}

By the end of the 20th century, there were two large creative unions, which included composers living in the Western and Eastern Siberia. Though established in different years - in 1942 in Novosibirsk and in 1983 in Krasnoyarsk they continue to form the musical space of the NorthernAsian region of Russia nowadays. Professional musicians of the country are well familiar with the alumni of Leningrad (currently Saint-Petersburg) Conservatory A. Novikov, G. Ivanov, Yu. Shchibanov, Yu. Yukechev, N. Lantuat, and O. Prostitov, as well as V. Senegin from Moscow Conservatory, Yu. Ashchepkov from Gnessin Russian Academy of Music. Creativity of Siberian composers in all academic genres in different years was different in intensity. At present, choral and symphonic music occupies a rather strong position, chamber (vocal and instrumental) music is enriched by the genres of "secular prayer"; synthetic genres vary in form and content while they include the "media" origin.

\section{A. Media Phenomenon and Its Appearance in Modern Culture}

Modern reality is characterized by the increasing amount of information flows. The invention of the typing machine started the whole era of visual perception of information, though the 20th century and its discoveries initiate audio perception [6]. What are these currently updated ways of information transfer? We observe the introduction of media (cinematic) art means in concert halls, education process, etc. The use of images (printed, musical texts, tables, diagrams, pictures - any images recorded as a description of information sources) projected by the video projector on the screens has become an integral part of the transfer of both scientific (technical) and artistic information.

\section{B. Forms of Audio Visuality in the Works of Siberian Composers}

The visualization methods can be different. One of the easiest and most accessible is the selection of the visual imagery for the previously written musical piece. This method is used for visualization of the music composition by I. Fleisher The Morning of Streltsy Execution based on the painting by Vasily Surikov: Music for oboe, percussion instruments, and string orchestra". There is a time period of 5 years between the musical and audiovisual versions. The media version was created with the support of the Main Directorate of Culture of Krasnoyarsk City in 2008 based in Siberian Federal University (SibFU) and presented on the website classic-online of I. Fleisher [7].

The Morning of Streltsy Execution by I. Fleisher without the media version can be considered as a program music inspired by the painting of the great Russian artist Vasily Ivanovich Surikov born in Krasnoyarsk. The art historian I. Doronchenko outlines the main peculiarity of the picture: the transfer of the "plurality" of actors, its "choral" fullness (with reference to the musical person, critic and contemporary of V. Surikov V. V. Stasov) [8].

The emotional tone of Fleisher's music is focused on two main images: a severe and gloomy image embodied in the tone of soloing kettledrums and the image of suffering condemned streltsy and the surrounding vivid crowd. The only recognizable theme is the theme of kettledrums. All other development is based on the continuously renewing melodic material. The sections with the solo of oboe alternate with exclamations of the kettledrums and the responses of the orchestra. The musical form gets rondality features due to the melodic formations in the oboe's part. These are not the repetitions of the musical material as it is typical for rondo, but the repetitions of the tone, which is close in its expressiveness to the tones of Russian folk instruments.

The medial version of the composition is enriched with new meanings, as music begins to illustrate the image. The audiovisual composition is framed with mute shots: titles and the picture as a whole. A ternary composition of the whole appears similar to an epic one:

\begin{tabular}{|c|c|c|}
\hline $\begin{array}{c}\text { A } \\
\text { PI (the image } \\
\text { of the whole picture) }\end{array}$ & $\begin{array}{c}\text { B } \\
\text { Audiovisual } \\
\text { composition }\end{array}$ & $\begin{array}{c}\text { PI (the image } \\
\text { of the whole picture) }\end{array}$ \\
\hline
\end{tabular}

The audiovisual composition uses different methods of showing the main participants of the events and places of execution. The movement of the camera changes: diagonally, up-down, to the left - to the right. Approaching and moving away allows to examine more closely the faces of the streltsy preparing for execution, the faces of women, children, soldiers, Tsar Peter, and his entourage. Kettledrums accompany the appearance of Peter and the symbols of his power: soldiers, entourage, gallows.

The images of the streltsy arouse more complicated feelings. The music is now perceived not only as a continuous flow of updates, while the role of repetitions is played by the image with the faces of the streltsy in white shirts and with candles in their hands, women (young, full of strength and old, taking everything stoically), a girl in a red kerchief, with horror and misunderstanding looking at what is happening.

Thus, the audiovisual version includes the regularities of musical forms - ternary and rondo (in visual demonstration), which are superposed on the free compositional plan of the music of this touching one-part instrumental piece.

Another approach and another result is observed in the electronic composition by Yu. Ashchepkov Heavenly Russia. Music to the video catalog of L. Klyuchnikova (2009). The composition was created directly after viewing each watercolor by L. Klyuchnikova as an art project, which was then repeatedly demonstrated in Novosibirsk and Moscow. The composer used the tone of the keyboard. Unusual sounds of stringed instruments and the choir performed on the keyboard organically combine with poetic and somewhat fantastic pictures of the heavenly world. Klyuchnikova's watercolor drawings are full of Orthodox churches with golden domes against the nature background.

The cycle of 14 parts is opened with a poetic epigraph, which reflects the aspiration for "moral perfection, spiritual ascent: When taken by an airplane / Beyond the clouds, 
beyond the dense thick smoke,/ The sky will get extremely blue for us, / The Sun will get extremely blue. / And that is why the wise man said:/ When putting down your roots on Earth, / Find time to look up in the sky / and let your eyes adjust" [9].

The musical composition reflects the logic of the pictures' arrangement: four sections, where each is a version of the previous one, reflects the variation principle typical for the music of domestic composers. Despite the analogy with M. Mussorgsky's piano cycle Pictures at an Exhibition, the cycle of Ashchepkov has its own unique and original composition, where the music and visual imagery often develop in parallel, without intersecting. Klyuchnikova's vivid manner determined as "mediative" has found adequate reflection in Ashchepkov's music. The sounds of the bells typical for the embodiment of the Russian origin, flickering images of the flowing air, chorality, lullaby: this is an incomplete list of the means used by the composer in the cycle.

Yu. Yukechev is distinguished among Siberian composers as a composer-innovator, an author of many electronic compositions written since 1980s. "Sonorant interpretation of the sound material, ostinato, pointillistic episodes, abundance of clusters, introduction of the sounds of nature in the general fabric of the piece" constitute the basis of Yukechev's electronic compositions" [10].

The interest for the visual imagery has been embodied in Yukechev's photo novels. The composer made photographs of the events he liked and places that he visited and then arranged them as videos with the music. His work with the image and with the sound resulted in the works of the synthetic genre in which both acoustic and electronic sounds are used.

One of the most vivid and recognizable photo novels is devoted to the victims of concentration camps The Holocaust. I. Bauer's words are used as an epigraph: "The memory of the Holocaust is necessary so that our children will never be victims, executioners or indifferent observers." The basis for the visual imagery of The Holocaust by Yukechev were the photographs that he had carefully chosen himself. Practically it is a documentary film where there are no comments, there are no texts, but there is only an image and music performed by Yukechev himself (piano) and drummer V. Borovsky (drum).

Using the capabilities of the instruments, their joint and separate sounds, the composer managed to create a unique in terms of strong impact 24-minute composition. From peaceful and happy faces on pre-war photos to mournful monuments to the victims of concentration camps through the terrible pictures of the humiliation of prisoners, the audience as if immerses in that cruel atmosphere thanks to the sounds that are tender and sorrowful, then desperately screaming.

\section{CONCLUSION}

There are not so many audiovisual compositions of Siberian composers that can be considered synthetic.
Transferring the composer's idea into the video requires either his own skills in creating videos, or collaborative work with a sound engineer and a videographer, which not everyone can arrange. At the same time, the attraction of the visual imagery greatly enriches the genre palette of composers, puts them in the conditions of choosing new means of expressiveness adequate to the visual imagery. Images in such compositions play the function of the program, which was previously performed by the text.

\section{REFERENCES}

[1] T. Shak, Methods of Cinematic Music Analysis in Terms of Musical Forms Development // Art Culture. - 2014 No. 1 (10) sias/ru/publicaitijns/magazines/kultura/2014-1/yazyki/845.html (Accessed on: 27.04.2018)

[2] A.V. Fedorov, Analysis of Audiovisual Mediatexts. Moscow, 2012, $182 \mathrm{p}$.

[3] T. Shak, Music in the Structure of the Media Text (on the Example of Feature and Animation Cinema): Author's Thesis, Doctor of Art History. Rostov-on-Don, 2010. 54 p.

[4] T. Ruban, Interconnection of Music and Art During the Pre-school Classes // Pedagogics of Art. - 2008, no.3

[5] V. N. Kholopova, Music as a Kind of Art: Student's book: recommended by the Ministry of Culture of the Russian Federation as a Student's Book for Art and Culture Universities. Saint-Petersburg: Lan: Music Planet, 2014, 320 p.

[6] Yu. R. Volfson and A. E. Volchina, Visual Perception in Modern Society or Where does the Gutenberg Galaxy? // Russian Journal of Education and Psychology. 2015. No.4 (48). URL: https://cyberleninka.ru/article/n/vizualnoe-vospriyatie-vsovremennom-obschestve-ili-kuda-dvizhetsya-galaktika-guttenberga (Accessed on: 29.04.2018)

[7] I. Fleisher, http://classic-online.ru/ru/production/53326

[8] I. Doronchenko, The Morning of the Streltsy Execution http://imperiya.by/video/zPntQhiYS9d/utro-streletskoy-kaznivasiliya-surikova.html (Accessed on: 29.04.2018).

[9] S.S. Goncharenko, Yury Ashepkov: The Happiness of Creativity // Novosibirsk Composers. Issue 2, Novosibirsk, 2016, p.13.

[10] L.L. Pylneva, Yu. P. Yukechev: Genre Overview, Periodization, Electronic Compositions. Lecture on the Course "History of Musical Culture of Siberia" (for Master students). Novosibirsk, 2006, p.13. 